\title{
Analisis Kinerja Operasional Angkutan Umum Kota Pare-Pare
}

\author{
Abd. Kadir Salim ${ }^{1}$, Asma Massara ${ }^{2}$, Zaifuddin³ ${ }^{3}$, M. Arzal ${ }^{4}$, Achmad Jumadi ${ }^{5}$ \\ 1,2,3,4,5 Program Studi Teknik Sipil Fakultas Teknik Universitas Muslim Indonesia, Indonesia \\ Jl. Urip Sumoharjo KM 05 Makassar, Sulawesi Selatan \\ Email: ${ }^{1}$ abdulkadir.salim@umi.ac.id, ${ }^{2}$ asma.massara@umi.ac.id, ${ }^{3}$ zaifuddin.zaifuddin@umi.ac.id, ${ }^{4}$ arzalmuhammad45@gmail.com, \\ s.achmadjumadii@gmail.com
}

\section{Kata Kunci \\ Angkutan umum, Kota Pare-Pare, Pelayanan, Standar Kinerja Operasional}

\begin{abstract}
Abstrak
Transportasi tidak dapat dipisahkan dari kehidupan umat manusia selama hal itu dibutuhkan dalam pendistribusian bahan, pergerakan aktifitas manusia maupun barang sebagai komponen mikro suatu perekonomian. Angkutan merupakan elemen penting dalam perekonomian karena berkaitan dengan distribusi barang, jasa, dan tenaga kerja, serta merupakan inti dari pergerakan ekonomi di kota, berbagai bentuk moda angkutan umum dengan karakteristik dan tingkat pelayanan yang diberikan mewarnai perkembangan sistem angkutan umum kota. Penelitian ini bertujuan untuk menganalisis kinerja operasional angkutan umum saat melayani para penumpangnya dengan pelayanan standar yang telah ditentukan. Dalam survei ini, diharapkan dapat bermanfaat bagi Pemerintah khususnya yang mengelola angkutan umum kota Pare-Pare, Ketersediaan jumlah armada trayek Lakessi - Lumpue lebih besar dari kebutuhan pergerakan penumpang, yang dapat ditunjukkan dari waktu antara (headway) dan lama perjalanan (waktu sirkulasi), untuk Trayek Lakessi-Lumpue ini adalah sebesar 20,45 menit, lama perjalanan dari Lakessi menuju Lumpue dan kembali ke Lakessi memerlukan waktu 108,30 menit atau 1:48 jam. Jadi Standar Kinerja Operasional Angkutan Umum kota Pare - Pare dapat dikatakan bahwa Angkutan Umum tersebut masih memenuhi standar.
\end{abstract}

\section{Abstract}

Transportation can't be separated from human life as long as it is needed in the distribution of materials, movement of human activities and goods as micro components of an economy.

Keywords

Public transport, the City of Pare-Pare, performance, the operational performance standards Transportation is an important element in the economy because it relates to the distribution of goods, services, and labor, and is the core of the economic movements in the city, various forms of public transport mode with the characteristics and level of service Given the development of the city's public transport system. This research aims to analyse the operational performance of public transport when serving its passengers with predefined service standards. In this survey, it is expected to benefit the Government, especially those who manage the public transportation of Pare-Pare city. The availability of a fleet of Lakessi-Lumpue routes is greater than the need for passenger movements, which can be demonstrated from the headway and length of travel (circulation time), for the Lakessi-Lumpue route is 20.45 minutes long, The journey from Lakessi to Lumpue and back to Lakessi takes 108.30 minutes or 1:48 hours. So, the public transport operational Performance standard of Pare-Pare can be said that the public transport still meets the standards.

\section{PENDAHULUAN}

Pembangunan atau pengembangan sarana transportasi dapat menimbulkan dampak positif terhadap suatu wilayah (Fisu, 2018) dan di sisi lain pertumbuhan aktivitas ekonomi akan mempengaruhi permintaan terhadap transportasi yang lebih banyak (Fisu. 2019). Kegiatan transportasi harus dilakukan secara menyeluruh dengan keterpaduan fisik antar moda berupa titik simpul pertemuan antar moda (Humang. 2016). Angkutan umum memiliki peranan penting dalam pembangunan perekonomian, untuk menuju keberlanjutan angkutan umum memerlukan penanganan serius. Angkutan merupakan elemen penting dalam perekonomian karena berkaitan dengan distribusi barang, jasa, dan tenaga kerja, serta merupakan inti dari pergerakan ekonomi di kota, berbagai bentuk moda angkutan umum dengan karakteristik dan tingkat pelayanan yang diberikan mewarnai perkembangan sistem angkutan umum kota yang seharusnya berorientasi kepada kenyamanan dan keamanan sehingga dapat bersaing dengan angkutan pribadi.

Pare-pare mempunyai arus lalu lintas dan mobilitas masyarakat yang sedang terutama pada saat pagi hari yang merupakan mulainya suatu aktivitas dan sore hari di saat mengakhiri aktivitasnya dan juga banyak kendaraan umum yang mengangkut penumpang melebihi kapasitas yang diijinkan. Hal ini memerlukan pelayanan transportasi yang memadai, baik jumlah maupun kemudahannya. Angkutan umum perkotaan 
adalah salah satu tulang punggung ekonomi perkotaan dimana kota yang 'baik' dan 'sehat' dapat ditandai dengan melihat kondisi sistem angkutan umum perkotaannya. Oleh karena itu, transportasi tidak dapat dipisahkan dari kehidupan umat manusia selama hal itu dibutuhkan dalam pendistribusian bahan, pergerakan aktifitas manusia maupun barang sebagai komponen mikro suatu perekonomian. Sektor transportasi harus mampu memberikan kemudahan bagi seluruh masyarakat dalam segala kegiatan di semua lokasi yang berbeda dan tersebar dengan karakter fisik yang berbeda pula.

Jadi dalam penelitian ini, akan mengambil suatu permasalahan pada Tranportasi Kota Pare-Pare dalam menganalisis mengenai kinerja operasional angkutan umum saat melayani para penumpangnya dengan pelayanan standar yang telah ditentukan. Dalam survei ini, diharapkan nanti dapat bermanfaat bagi Pemerintah khususnya yang mengelola angkutan umum kota Pare-Pare. Di Kota Pare-Pare terdapat masalah yang terjadi pada angkutan umum dikarnakan adanya kelebihan armada maupun ketidaklayakan angkutan dan sangat minim masyarakat yang menggunakan angkutan umum tersebut. Sehingga belum optimal kinerjanya maka dibutuhkan analisis kinerja operasional dari angkutan umum di Kota Pare-Pare. Karena sangat pentingnya peran dari transportasi pada angkutan umum, maka akan dilakukan analisis kinerja operasional melalui peraturan (Word Bank 1987 dan Dirjen-Hubdat) yang diatur tentang pedoman teknis penyelenggara angkutan umum.

Adapun tujuan dari penelitian yang ingin dicapai adalah sebagai berikut:

1. Untuk mengetahui pelayanan Kinerja Operasional Angkutan Umum Kota Pare - Pare di Sulawesi Selatan

2. Untuk mengetahui Standar Operasional Angkutan Umum Kota Pare - Pare.

\section{METODE PENELITIAN}

\subsection{Tempat Penelitian}

Penelitian ini dilaksanakan di kota Pare-Pare, Provinsi Sul-Sel pada:
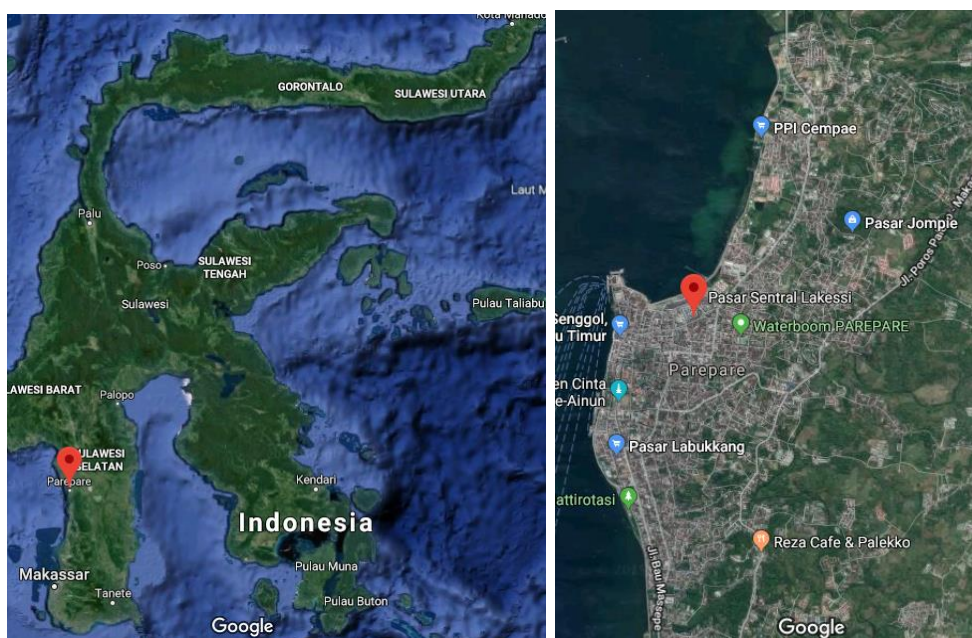

Gambar 1. Peta Lokasi Penelitian Kota Pare Pare, Pasar Lakessi (Google maps)

Batas-batas Wilayah Kota Pare-Pare :
A. Sebelah Utara
: Jalan Poros Pare - Pinrang
B. Sebelah Selatan
: Jalan Poros Palopo-Makassar
C. Sebelah Barat
: Laut Selat Makassar
D. Sebelah Timur
: Persawahan

\subsection{Jenis Data}

Metode penelitian pada dasarnya merupakan cara ilmiah untuk mendapatkan data dengan tujuan tertentu. Agar pelaksanaan penelitian dapat dilakukan dengan benar maka metode penelitian yang dilakukan harus direncanakan secermat dan setepat mungkin. Dalam penulisan skripsi ini metode pengambilan data dilakukan untuk dua jenis data, yaitu:

1. Data primer

Data Primer adalah data yang diperoleh dengan melakukan survei langsung di lapangan. Pengambilan data primer dilakukan selama tujuh hari dengan durasi waktu 8 jam/hari, setiap harinya dengan variabel berikut : 
2. Data sekunder

a. Waktu antara (Headway), diperoleh dengan menggunakan stopwatch.

b. Frekuensi, didapatkan dengan mengamati kendaraan.

c. Waktu perjalanan, diketahui dari dalam angkutan yang bergerak.

d. Kecepatan perjalanan, dihitung dari laju perjalanan angkutan $\mathrm{km} / \mathrm{jam}$.

e. Waktu sirkulasi, ditinjau dari rute awal ke rute akhir dan kembali.

f. Faktor muatan, ditinjau dari banyaknya kapasitas sebuah angkutan.

g. Kapasitas operasi, di persentasekan jumlah angkutan yang beroperasi.

h. Kebutuhan jumlah armada, dipengaruhi jumlah penumpang perjam, frekwensi, headway, waktu tempuh kendaraan serta kapasitas angkutan

Merupakan data-data pendukung yang diperoleh dari instansi-instansi terkait, mengenai kinerja operasional angkutan umum atau dapat juga diperoleh dengan mencari informasi dari peraturan perda pemerintah yang terkait dengan hal-hal yang akan dianalisis.

Metode yang digunakan dalam studi ini adalah metode analisis deskriptif. Metode analisis deskrikriptis yaitu suatu metode yang berfungsi untuk mendeskripsikan atau memberi gambaran terhadap objek yang diteliti melalui data atau sampel yang telah terkumpul, dengan kata lain penelitian analis deskriptif mengambil masalah atau memusatkan perhatian kepada masalah-masalah sebagaimana adanya saat penelitian dilaksanakan, hasil penelitian yang kemudian di olah dan di analisis untuk diambil kesimpulannya.

\section{HASIL DAN PEMBAHASAN}

Adapun hasil pengolahan data dalam bentuk analisis adalah sebagai berikut :

Angkutan yang diteliti adalah operator angkutan dari dan ke Lakessi menuju 4 wilayah studi yang diamati yaitu Lapadde, Perumnas, Soreang, dan Lumpue. Data primer yang digunakan merupakan data yang didapat dari pengamatan langsung dan perhitungan dilapangan.

Titik pengamatan adalah titik pemberhentian angkutan disepanjang jalan yang dilewati rute proyek Titik pengamatan ini adalah tempat yang menjadi titik pemberhentian trayek Lakessi - Lapadde, Lakessi Perumnas, Lakessi - Soreang dan Lakessi - Lumpue. Penelitian ini dilakukan dengan pengumpulan data dilapangan secara manual, yaitu pengamatan langsung dilapangan. Data yang didapat dari hasil pengamatan : Trayek dalam hasil pengamatan Lakessi - Lapadde dapat dilihat pada Tabel 1. dan Gambar 2. yaitu :

Tabel 1. Titik Pengamatan Dalam Tiap Trayek

\begin{tabular}{|l|l|}
\hline \multirow{4}{*}{ Lakessi - Lapadde } & Poros Sidrap-Pare \\
\cline { 2 - 2 } & Lapadde \\
\cline { 2 - 2 } & Universitas Pare-Pare \\
\cline { 2 - 2 } & Jln. Jend. Ahmad Yani \\
\cline { 2 - 2 } & Jln. Karaeng Burane \\
\cline { 2 - 2 } & Jln. Sultan Hasanuddin \\
\cline { 2 - 2 } & Pasar Senggol \\
\cline { 2 - 2 } & Jln. Lasinrang \\
\cline { 2 - 2 } & Lakessi \\
\hline
\end{tabular}

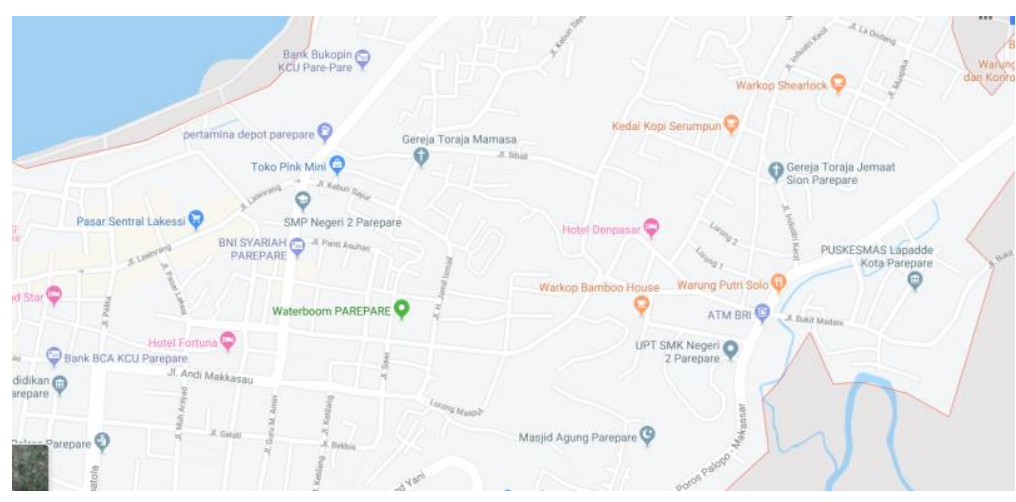

Gambar 2. Trayek Lakessi - Lapadde (Google Maps) 
Trayek dalam hasil pengamatan Lakessi - Perumnas dapat dilihat pada Tabel 2. dan Gambar 3. yaitu :

Tabel 2 Titik Pengamatan Dalam Tiap Trayek

\begin{tabular}{|l|l|}
\hline \multirow{4}{*}{ Lakessi - Perumnas } & Perumnas Wekke'e \\
\cline { 2 - 2 } & Jln. Garuda \\
\cline { 2 - 2 } & Jln. Lasangga \\
\cline { 2 - 2 } & Jln. Jend. Ahmad Yani \\
\cline { 2 - 2 } & Jln. Karaeng Burane \\
\cline { 2 - 2 } & Jln. Sultan Hasanuddin \\
\cline { 2 - 2 } & Jln. Baso Dg Patompo \\
\cline { 2 - 2 } & Lakessi \\
\hline
\end{tabular}

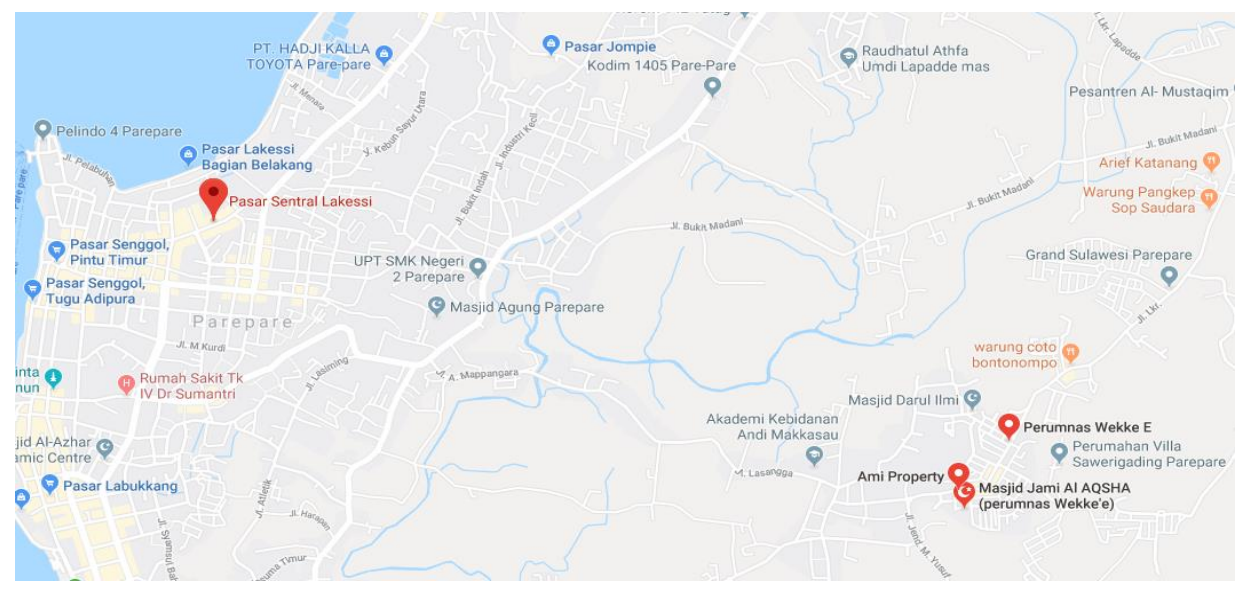

Gambar 3 Trayek Lakessi - Perumnas (Google Maps)

Trayek dalam hasil pengamatan Lakessi - Soreang dapat dilihat pada Tabel 3. dan Gambar 4. yaitu :

Tabel 3 Titik Pengamatan Dalam Tiap Trayek

\begin{tabular}{|l|l|}
\hline \multirow{4}{*}{ Lakessi - Soreang } & Poros Pinrang-Pare \\
\cline { 2 - 3 } & Jln.H. Andi. Muhammadiyah \\
\cline { 2 - 2 } & Jln. Lahalede \\
\cline { 2 - 3 } & Jln. Karaeng Burane \\
\cline { 2 - 2 } & Jln. Sultan Hasanuddin \\
\cline { 2 - 2 } & Pasar Senggol \\
\cline { 2 - 2 } & Jln. Lasinrang \\
\cline { 2 - 2 } & Lakessi \\
\hline
\end{tabular}

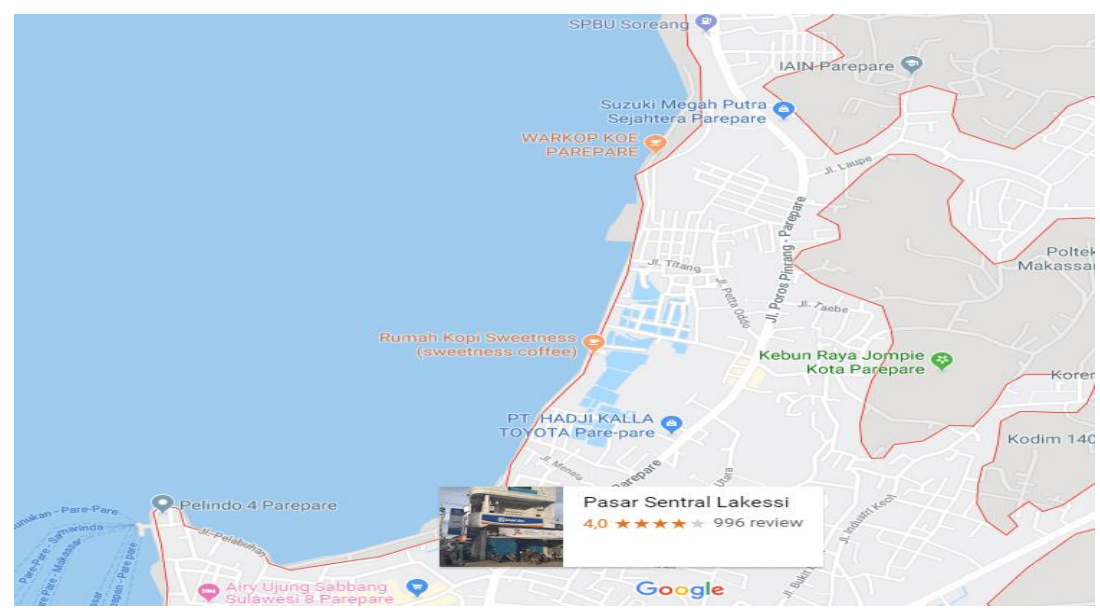

Gambar 4 Trayek Lakessi - Soreang (Google Maps) 
Trayek dalam hasil pengamatan Lakessi - Lumpue dapat dilihat pada tabel 4. dan Gambar 5. yaitu :

Tabel 4. Titik Pengamatan Dalam Tiap Trayek

\begin{tabular}{|l|l|}
\hline \multirow{4}{*}{ Lakessi - Lumpue } & Poros Makassar-Pare \\
\cline { 2 - 2 } & Jln. Mattiro Tasi \\
\cline { 2 - 2 } & Jln. Bau Massepe \\
\cline { 2 - 2 } & Jln. H. Agussalim \\
\cline { 2 - 2 } & Jln. Abdul Kadir \\
\cline { 2 - 2 } & Jln. Andi Cammi \\
\cline { 2 - 2 } & Jln. Sultan Hasanuddin \\
\cline { 2 - 2 } & Pasar Senggol \\
\cline { 2 - 2 } & Jln. Lasinrang \\
\cline { 2 - 2 } & Lakessi \\
\hline
\end{tabular}

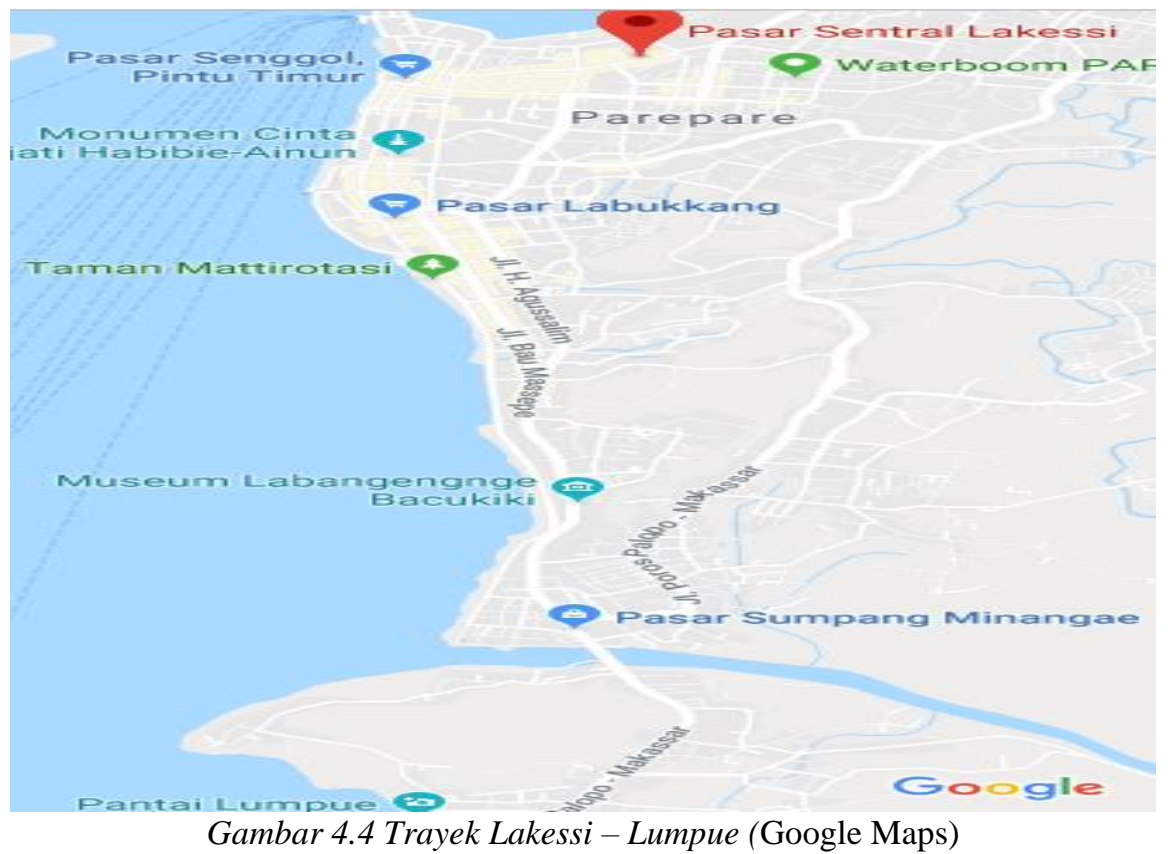

\section{Waktu Antara (Headway)}

Pelaksanaan survey tugas akhir ini dilakukan selama 2 hari dengan waktu pengamatan pagi, siang dan sore hari. Nilai headway dapat diperoleh dengan rumus :

$$
[\mathrm{H}=\mathrm{T} 2-\mathrm{T} 1]
$$

Keterangan :

$\mathrm{H}=$ headway (menit)

$\mathrm{T} 1$ = waktu kedatangan angkutan pertama

$\mathrm{T} 2$ = waktu kedatangan angkutan kedua 
Dari hasil pengamatan data setiap trayek diperoleh headway rata rata untuk setiap trayek yang dapat dilihat pada Gambar 6. yaitu:

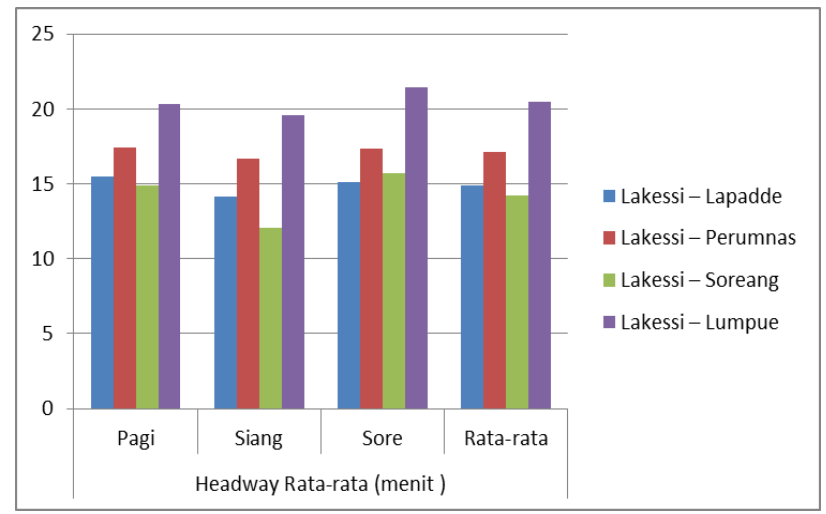

Gambar 6. Headway rata-rata

\section{Waktu Perjalanan}

Dari hasil pengamatan data dilapangan pada pagi, siang dan sore hari selama 2 hari diperoleh waktu perjalanan rata- rata dari hasil pengamatan ditunjukkan pada Gambar 7 yaitu :

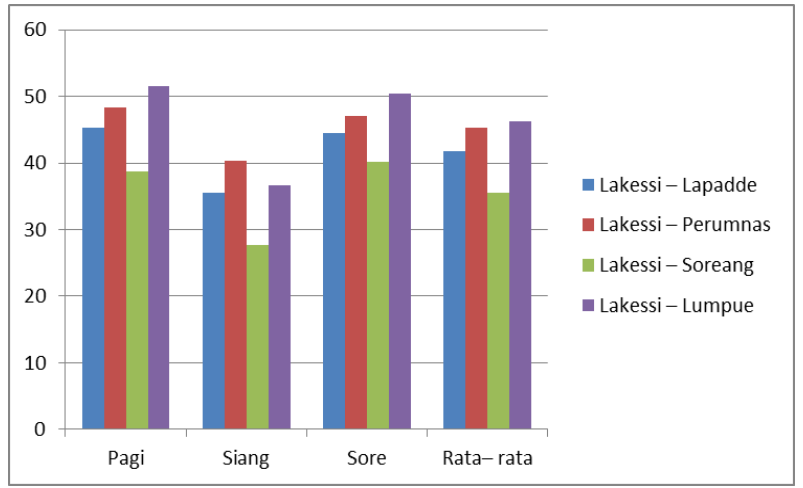

Gambar 7. Waktu Perjalanan rata-rata

Kecepatan Perjalanan

Jalur trayek angkutan pedesaan pada penelitian ini berada pada kawasan perkotaan sehingga dapat dikatakan berada pada kepadatan minimum. Dari hasil pengamatan dan pengolahan data diperoleh rata rata untuk setiap trayek seperti pada Gambar 8 yaitu :

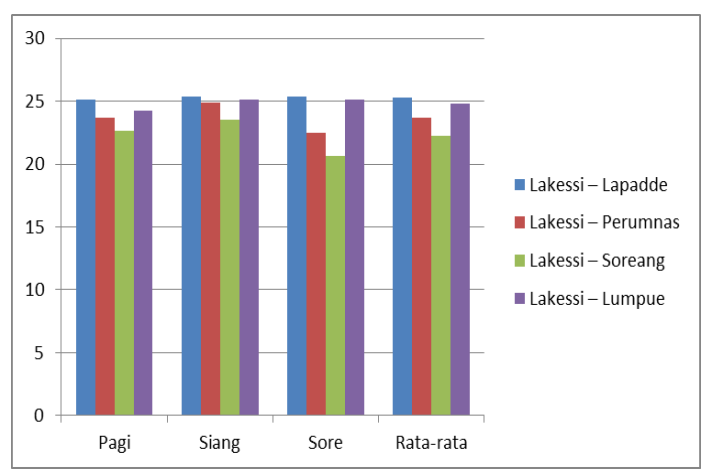

Gambar 8. Waktu Perjalanan rata-rata 


\section{Waktu Sirkulasi}

Waktu sirkulasi rata-rata angkutan pedesaan hasil pengamatan dilapangan untuk tiap trayek dapat dilihat pada Gambar 9 yaitu :

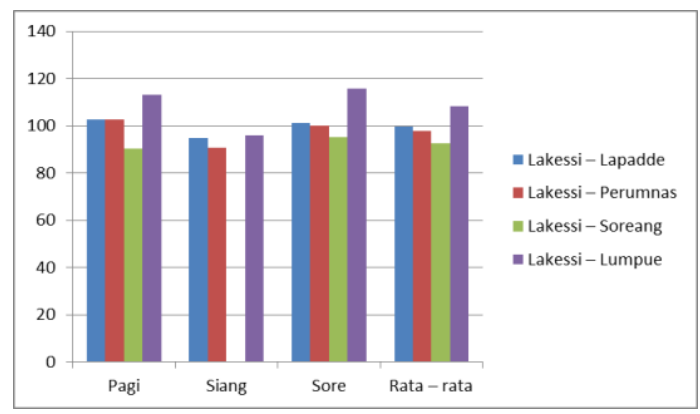

Gambar 9. Waktu Sirkulasi rata-rata

\section{Faktor Muatan (Load Faktor)}

Dari hasil pengamatan dan pengolahan data dapat dilihat pada grafik berikut. Diperoleh Load Faktor angkutan pedesaan rata-rata untuk setiap trayek ditunjukkan pada Gambar 10 yaitu:

Kapasitas Operasi (Availability)

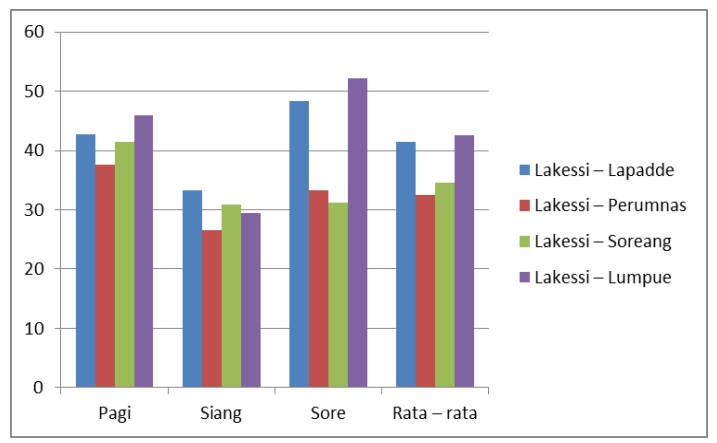

Gambar 10. Load Faktor rata-rata

Kinerja pelayanan angkutan pedesaan ditinjau dari kapasitas operasi (availability) ditunjukkan pada Gambar 11 yaitu :

Kebutuhan Jumlah Armada.

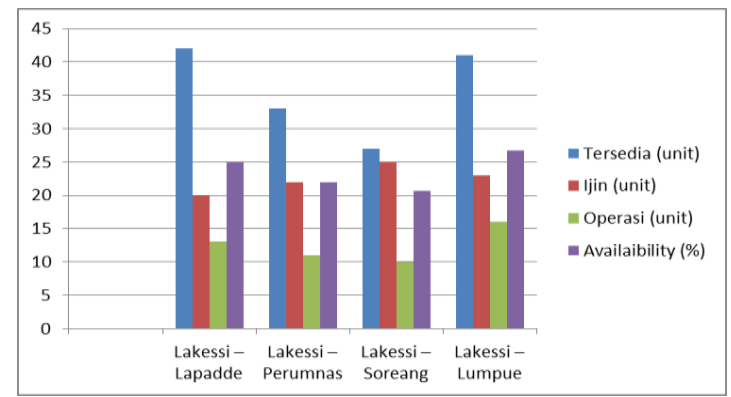

Gambar 11. Kapasitas Operasi rata-rata

Jumlah kebutuhan armada per-waktu sirkulasi maupun per-periode jam sibuk dipengaruhi oleh jumlah penumpang perjam, frekwensi, Headway ,Waktu tempuh kendaraan serta kapasitas angkut kendaraan.

Dari hasil analisa maka jumlah armada yang dibutuhkan berdasarkan waktu sirkulasi dapat dihitung sebagai berikut:

\section{Lakessi - Lapadde}

Menghitung kebtuhan armada yang dibutuhkan pada jam sibuk pagi :

$$
\mathrm{K}=\frac{C T}{H \times f A}
$$




$$
\begin{aligned}
& \mathrm{K}=\frac{101.23}{15.45 \times 100}=6.62 \\
& \mathrm{~K}^{\prime}=K \times \frac{W}{C T a b a} \\
& \mathrm{~K}^{\prime}=6.62 \times \frac{120}{101.23}=7.84 \\
& \approx \mathrm{K}^{\prime}=8
\end{aligned}
$$

Lakessi - Perumnas

Menghitung kebutuhan armada yang dibutuhkan pada jam sibuk pagi :

$$
\begin{aligned}
\mathrm{K} & =\frac{C T}{H \times f A} \\
\mathrm{~K} & =\frac{130,68}{17,81 \times 100}=7,34 \\
\mathrm{~K}^{\prime} & =K \times \frac{W}{C T a b a} \\
\mathrm{~K}^{\prime} & =7,34 \times \frac{120}{130,68}=6,74 \\
\approx \mathrm{K}^{\prime} & =7
\end{aligned}
$$

Lakessi - Soreang

Menghitung kebutuhan armada yang dibutuhkan pada jam sibuk pagi :

$$
\begin{aligned}
\mathrm{K} & =\frac{C T}{H \times f A} \\
\mathrm{~K} & =\frac{142,93}{15,87 \times 100}=9,01 \\
\mathrm{~K}^{\prime} & =K \times \frac{W}{C T a b a} \\
\mathrm{~K}^{\prime} & =9,01 \times \frac{120}{142.93}=7,56 \\
\approx \mathrm{K}^{\prime} & =8
\end{aligned}
$$

Lakessi - Lumpue

Menghitung kebutuhan armada yang dibutuhkan pada jam sibuk pagi :

$$
\begin{aligned}
\mathrm{K} & =\frac{C T}{H \times f A} \\
\mathrm{~K} & =\frac{173,30}{8,94 \times 100}=19,6 \\
\mathrm{~K}^{\prime} & =K \times \frac{W}{C T a b a} \\
\mathrm{~K}^{\prime} & =19,6 \times \frac{120}{173,30}=13,42 \\
\approx \mathrm{K}^{\prime} & =13
\end{aligned}
$$




\section{PENUTUP}

\subsection{Kesimpulan}

Berdasarkan hasil pengelolaan data dan juga analisis diperoleh kesimpulan yaitu kinerja pelayanan angkutan umum yang beroperasi di Kabupaten Kota Pare - Pare Sulawesi Selatan yaitu Ketersediaan jumlah armada trayek Lakessi - Lumpue lebih besar dari kebutuhan pergerakan penumpang, yang dapat ditunjukkan dari waktu antara (headway) dan lama perjalanan (waktu sirkulasi). Waktu antara untuk Trayek LakessiLumpue ini adalah sebesar 20,45 menit. Berdasarkan ketentuan dari Dirjen Perhubungan Darat, waktu antara yang disyaratkan maksimum 10-20 menit, sehingga ditinjau dari waktu antara, maka angkutan kota trayek Lakessi - Lumpue ini menunjukkan syarat kurang baik. Sedangkan untuk waktu sirkulasi, lama perjalanan dari Lakessi menuju Lumpue dan kembali ke Lakessi memerlukan waktu 108,30 menit atau 1:48 jam. Waktu sirkulasi ini dapat dikatakan kurang baik sesuai ketentuan dari persyaratan Dirjen Perhubungan Darat yaitu maksimum sebesar 2 jam. Jadi Standar Kinerja Operasional Angkutan Umum kota Pare - Pare dapat dikatakan bahwa Angkutan Umum tersebut masih memenuhi standar menurut (World Bank 1987 dan DirjenHubdat).

\subsection{Saran}

Berdasarkan analisis dan kesimpulan sebelumnya, disarankan :

1. Perlu dilakukan studi lanjut tentang penyebab kelebihan angkutan umum yang tidak beroperasi di Kabupaten Pare - pare.

2. Perlu dilakukan pencabutan ijin operasional angkutan umum, apabila secara fisik kendaraan sudah tidak layak jalan.

3. Menjadi acuan pada pemerintah untuk mengambil kebijakan untuk mengatasi kelebihan dari jumlah angkutan tersebut.

\section{DAFTAR PUSTAKA}

Departemen Perhubungan, 2001, Panduan Pengumpulan Data Angkutan Umum Perkotaan, Penerbit Direktorat Bina Sistem Lalu Lintas dan Angkutan Kota, Jakarta

Ekawati Happy Hanifah. (2008), Studi Evaluasi Terminal Kota Pacitan. Pacitan.

Fisu AA. (2018). Analisis Kebutuhan Fasilitas Sisi Laut Pelabuhan terminal Khusus PLTGU Lombok. PENA TEKNIK: Jurnal Ilmiah Ilmu-ilmu Teknik Vol 3 No 2, 197 - 206.

Fisu AA. (2019). Tinjauan Kecelakaan lalu Lintas Antar Wilayah Pada Jalan Trans Provinsi Sulawesi Selatan. PENA TEKNIK: Jurnal Ilmiah Ilmu-ilmu Teknik Vol 4 No 1, 53 - 65.

Humang Windra Priatna \& Zulfadly. (2016). Analisis Keterpaduan Moda Transportasi Angkutan Penyeberangan dangan Jalan Raya di pelabuhan Bajoe Kab. Bone. PENA TEKNIK: Jurnal Ilmiah Ilmu-ilmu Teknik Vol 1 No 1, 27 - 38.

Natsir, Rakhmawati (2016). Karakteristik kinerja Moda Angkutan Umum Kota Palopo (Studi Kasus Penumpang Bus Executive, Suspensi Udara, Scania - PO Bintang Prima. PENA TEKNIK: Jurnal Ilmiah Ilmu-ilmu Teknik Vol 1 No 2, 155 - 162.

Keputusan Menteri Perhubungan Nomor 31 Tahun 1995 Tentang Transportasi Jalan. Jakarta : Kementerian Perhubungan RI.

Keputusan Direktur Jenderal Perhubungan Darat Nomor : SK.687 / AJ.206 /DRDJ /2002. Pedoman Teknis Penyelenggaraan Angkutan Penumpang Umum Di Wilayah Perkotaan Dalam Trayek Tetap dan Teratur. Jakarta ; Departemen perhubungan RI.

Sukmadinata, (2006), Metode Penelitian Deskriptif, Bandung.

Undang - undang Republik Indonesia No.14 tahun 1992 Tentang Lalu Lintas dan Angkutan Jalan, Jakarta.

Undang - Undang Republik Indonesia Nomor 22 Tahun 2009, Lalu Lintas Dan Angkutan Jalan, Pemerintah Republik Indonesia

Peraturan Menteri Perhubungan Republik Indonesia Nomor 98 tahun 2013, Standar Pelayanan Minimal Angkutan Orang Dengan Kendaraan Bermotor Umum Dalam Trayek, Menteri Perhubungan Republik Indonesia.

Warpani, Suwardjoko P., (2002), Pengelolaan Lalu Lintas dan Angkutan Jalan. Bandung: ITB.

World Bank. 1987. Bus Service : Reducing Cost and Raising Standarts. Washington DC : World Bank Technical Paper No.68 